\title{
Leituras prescritas e práticas de leitura de estudo no ensino superior
}

\author{
Elaine Cristina Liviero Tanzawa \\ Elsa Maria Mendes Pessoa Pullin
}

\begin{abstract}
Resumo
Uma das responsabilidades educativas de bibliotecários e de professores é a de contribuírem para a formação de novos leitores. Raramente, em cursos de graduação, a produção e as condições de leitura têm sido levadas em conta pelos professores. Este trabalho objetivou identificar os modos de ler, as razões e as preocupações de alunos ingressantes e formandos dos cursos que certificam esses profissionais, quando estudam a partir dos textos prescritos por seus professores. Participaram 112 alunos, matriculados em Biblioteconomia e Pedagogia. A coleta de informações foi realizada por meio de um questionário. Os dados foram analisados quantitativa e qualitativamente. Os resultados ressaltam a importância dos cuidados que os professores devem ter quando selecionam, prescrevem e trabalham em sala de aula, expondo, discutindo e avaliando os assuntos dos textos que prescrevem, visto que tais cuidados parecem interferir nos modos, razões e preocupações dos alunos quando leem textos de estudo.
\end{abstract}

Palavras-chave: Leitura, estudantes, ensino superior.

\section{Prescribed reading and study reading practices in Higher Education}

\begin{abstract}
One of the educational responsibilities of librarians and teachers is to contribute to the education of new readers. Reading conditions have rarely been taken into account by Professors, in undergraduate courses. In this study we aim at identifying ways of reading, reasons and concerns of new students and graduates of the courses that certify these professionals who study texts prescribed by professors. We took 112 students enrolled in Library Science and Pedagogy. We gather information from answers to a questionnaire. The data were analyzed quantitatively and qualitatively. The results reveal the importance of care that Professors should have when they select, prescribe, expose, discuss and evaluate prescribed texts in the classroom. Such care with these issues may interfere students' ways, reasons and concerns when reading textbooks.
\end{abstract}

Keywords: Reading, students, higher education.

\section{Lecturas prescritas y prácticas de lectura de estudio en la Enseñanza superior}

\section{Resumen}

Una de las responsabilidades educativas de bibliotecarios y de docentes es contribuir para la formación de nuevos lectores. Raros son los casos en que los docentes consideran la producción y las condiciones de lectura en cursos de pregrado. Este trabajo tuvo como objetivo identificar los modos de leer, las razones y las preocupaciones de alumnos que ingresan y alumnos prestes a egresar de las facultades que diploman estos profesionales cuando estudian por medio de textos prescritos por sus profesores. Participaron 112 alumnos matriculados en Biblioteconomía y Pedagogía. La recolección de datos se realizó por medio de un cuestionario e su análisis fue cuantitativo y cualitativo. Los resultados resaltan la importancia del cuidado que los docentes deben dispensar al seleccionar, prescribir y trabajar en aula los textos indicados. Considerando que tal cuidado parece interferir en los modos, razones y preocupaciones de los alumnos cuando leen los textos de estudio, los docentes deben también exponer, discutir y evaluar los temas de los textos que prescriben.

Palabras clave: Lectura, estudiantes, educaciónón superior. 


\section{Introdução}

No Brasil, apesar do aumento significativo de oportunidades educacionais pela oferta de vagas nos diversos níveis de ensino (Gomes \& Boruchovitch, 2009), as exigências das sociedades modernas para a participação ativa dos cidadãos estão longe de serem atendidas, especialmente as relacionadas à competência e prática de leitura da população (Amorim, 2008).

Entre os fatores que coexistem na produção do êxito ou do fracasso escolar, em qualquer nível de ensino, os relacionados à competência em ler os textos previstos para estudo afetam frequentemente os níveis de desempenho dos alunos.

No Ensino Superior, a leitura é um dos elementos essenciais para o desempenho acadêmico, pelo fato de se exigir que o aluno tenha uma metodologia individual, autônoma e eficiente de leitura. Desse aluno se espera que assuma a posição de coautor na construção dos conhecimentos legitimados nessas instituições e demonstre um perfil de leitor-acadêmico (Dauster, 2003).

No entanto, não é incomum constatar-se que esses alunos enfrentam obstáculos para lerem os textos indicados por seus professores. Alguns desses obstáculos decorrem de posturas e, por vezes, de avaliações equivocadas. As palavras de Carlino (2003, p. 1) são pontuais quanto a isso: "o caráter implícito do conhecimento contido nos textos como as práticas leitoras, que os docentes consideram naturais (e não culturais), colocam obstáculos ao desenvolvimento de muitos estudantes". Outros deles procedem da não compreensão dos alunos sobre o que leem, a qual compromete a reflexão, a tomada de posição e a proposição de novas conclusões sobre o que sabem.

A leitura no Ensino Superior tem-se constituído em uma temática de interesse de diferentes campos disciplinares (Witter, 1996). Produções anteriores (Barzotto, 2005; Silva \& Witter, 2008; Vicentelli, 1999) sugerem que a leitura esteja diretamente relacionada com o desempenho escolar de universitários.

Como nos lembra Oliveira (1999), ao longo do curso de graduação, os alunos sentem, com intensidade maior do que a vivenciada em sua escolarização anterior, a necessidade de serem bons leitores. Sentimentos de fracasso são por eles relatados, muitas vezes informalmente, sobre a impossibilidade de darem conta da quantidade de textos prescritos, ou por não adiantar lê-los, porque não os compreendem. Possivelmente, tal ocorra, porque não tiveram a oportunidade de, em sua formação leitora, terem sido instigados a ler criticamente, ou alfabetizados a ler textos científicos (Carlino, 2003; Witter, 1992). Para muitos desses alunos, além do tipo de texto, a frequência e o tempo prescritos para trabalharem os textos de estudo configuram situações para as quais não foram preparados (Credé \& Kuncel, 2008). A escolarização que usufruíram antes do ingresso em cursos de graduação parece ser uma das razões do não preparo desses alunos para responderem adequadamente a tais condições e exigências presentes nos contextos que passam a vivenciar no Ensino Superior (Carlino, 2003).
Resultados de pesquisas sobre o grau de compreensão obtido por alunos de distintos níveis de escolarização demonstram que as dificuldades não ocorrem apenas entre os do Ensino Fundamental e Médio, mas também entre os de Ensino Superior (Cunha \& Santos, 2006). Como ponderam Oliveira, Santos \& Primi (2003), o vestibular tem permitido entrada a alunos não suficientemente preparados para frequentar cursos de graduação.

Levando em conta essas considerações, entendemos que esforços devem ser empreendidos, inclusive nesse nível de ensino, para dirimir tais dificuldades. Esforços conjuntos de todos os professores poderão propiciar ocasião para a remediação do baixo nível de compreensão em leitura (Oliveira e cols., 2003), nomeadamente porque desses alunos se espera que sejam capazes de demonstrar "pensamento crítico desenvolvido e maior conhecimento sobre si mesmos, de forma a possuírem condições de tomar decisões" (Oliveira e cols., 2003, p. 20), quando concluírem seus cursos.

Apesar de raramente constatado em investigações (Barzotto, 2005; Carlino, 2003; Pullin, 2007; Pullin \& Tanzawa, 2009; Witter, 1996) continua comum, especialmente entre os professores que atuam em cursos de graduação, a crença de que, quando o aluno ingressa em cursos de graduação, disponha em seu repertório das habilidades necessárias à leitura dos textos selecionados e por eles prescritos para o cumprimento das atividades das disciplinas do curso.

Como ressaltado, no Ensino Superior, o desempenho do ofício de aluno exige, além da leitura desses textos, como uma das alternativas para aprender a de que assuma "posturas argumentativas e críticas" (Joly \& Paula, 2005, p. 33) que the propiciem condições de autoria nas diferentes produções acadêmicas (orais e escritas) que deve realizar.

Entretanto, muitos alunos do Ensino Superior desconhecem o gênero de textos que Ihes é prescrito para estudo. Tratam-se de textos teóricos e de relato de pesquisas, que por suas características foram denominados por Carlino (2003) de textos acadêmicos, porque são "derivados de textos científicos não escritos para eles, mas para quem conhece as linhas de pensamento e as polêmicas internas de cada campo de estudo" (Carlino, 2003, p. 1). Para que os alunos possam lê-los, precisam conhecer, além dos termos técnicos específicos de cada campo disciplinar, a estrutura e os recursos linguísticos admissíveis pela comunidade disciplinar na qual e para a qual o texto foi produzido (Mostafa, 2004; Witter, 1992). A pouca, quando não a ausência de experiência de leitura desses textos, foi registrada no estudo de Bartalo (1997).

Por conseguinte, os professores desses alunos deveriam, quando selecionam a bibliografia que irão adotar, analisar a complexidade do gênero do texto e demonstrarem estar cientes de que o processo de alfabetização não se reduz ao domínio das tecnologias da escrita da língua materna, ensinadas nos primeiros anos da escolarização. A alfabetização é um processo contínuo, multidimensional e plural, que se inscreve em múltiplos campos e que exige do indivíduo diferentes habilidades e domínios. Entre esses, os relacionados à língua materna e a línguas estrangeiras, em suas diferentes produções, aos da escrita específica comum 
em campos disciplinares, como da matemática, da química e da física, além das habilidades relativas ao uso dos recursos possibilitados por sistemas virtuais, como os da World Wide Web (Web). Isso, restringindo a leitura aos produtos das tecnologias da escrita, no que importa para este estudo, visto esses artefatos serem frequentemente os indicados como fonte de estudo em cursos de graduação.

\section{Prescrição de leituras de estudo}

Os textos que possibilitam a realização das atividades escolares costumeiramente são indicados por professores. Vimos que algumas crenças regulam essas prescrições (Carlino, 2003). Porém, nem sempre as atitudes e cuidados necessários são tomados pelos professores, apesar de que se saiba que o valor atribuído pelo professor à leitura dos textos que indica pode delimitar a emergência da motivação intrínseca para que o aluno aprenda e realize as tarefas que Ihe sejam prescritas.

Freire (1982) observou que toda a prescrição de leitura de estudo deve refletir "uma intenção fundamental de quem a elabora: a de atender ou a de despertar o desejo de aprofundar conhecimentos naqueles ou naquelas a quem é proposta" (Freire, 1982, p. 9). No caso de não atender e despertar esse interesse, os leitores para os quais a leitura foi indicada não serão motivados a realizá-la.

Preocupado com as condições efetivas de realização da leitura na escola, Silva (1996) sugeriu alguns cuidados que os professores devem ter quando da indicação dos textos para os alunos lerem, qualificando-os como imprescindíveis. Ressaltou que o texto deve ser significativo para o aluno. Para que tal ocorra, os modos pelos quais ele é prescrito devem viabilizar que o aluno identifique a importância do texto para sua formação e o instiguem a relacionar as informações do texto com o que sabe a respeito. A clareza quanto a essa importância e dos objetivos que deve alcançar a partir dessa leitura, além do uso de estratégias eficientes de leitura possibilitarão que se preocupe em compreender, isto é, ir além do entendimento e da interpretação superficial do texto.

Em face da relevância da leitura para a formação pessoal e profissional, buscamos, no presente trabalho, caracterizar a opinião de alunos universitários acerca das leituras indicadas/prescritas por seus professores. Pela importância estratégica para a formação de novos leitores no contexto escolar, especialmente nos anos iniciais do Ensino Fundamental, decidimos escolher alunos dos cursos de Biblioteconomia e de Pedagogia, dada a certificação profissional que oportunizam.

\section{Método}

Um total de 112 alunos matriculados nos cursos de Biblioteconomia $(n=62)$ e de Pedagogia $(n=50)$, de uma universidade pública, participou deste estudo. Para a seleção dos alunos-participantes, as respectivas populações foram reduzidas aos alunos matriculados no $1^{\circ}$ ano e no $4^{\circ}$ ano desses cursos.

Tendo por marco o curso, formamos dois grupos: GB com os participantes do curso de Biblioteconomia e GP com os de Pedagogia. Os participantes do $1^{\circ}$ ano, matriculados no curso de Biblioteconomia e Pedagogia, constituíram os subgrupos GB1 $(n=32)$ e GP1 $(n=28)$, respectivamente. Por sua vez, os participantes do $4^{\circ}$ ano compuseram os subgrupos GB2 $(n=30)$ e GP2 $(n=22)$. Todos os alunos que aceitaram colaborar com a pesquisa assinaram o Termo de Consentimento Livre e Esclarecido e constituíram o conjunto de participantes.

\section{Instrumento}

Foi utilizado o questionário desenvolvido por Pullin (2006) intitulado "Prescrições e Práticas de Leitura de Textos de Estudo", que teve por fonte os resultados e ponderações de Chartier, Debayle, \& Jachimowicz (1993), Fraisse (1993) e Kons (2005). O questionário é composto por 20 itens, 16 deles seguidos por opções apresentadas sob a modalidade de escala Likert, três para a seleção da opção sim e não, e um item para a escolha de uma das quatro opções apresentadas. Uma instrução escrita precede os itens do questionário, a qual solicita ao respondente que tenha como foco os textos indicados por seus professores atuais.

A testagem desse questionário junto a populações similares ao deste estudo foi realizado por Pullin (2006). Para este trabalho, recortamos para análise as respostas dos participantes a oito itens, os quais visam identificar as preocupações que os acompanham enquanto leem esses textos, as fontes que regulam o interesse para realizar as leituras prescritas, bem como sua opinião quanto ao uso desses textos nas discussões em sala de aula e nas avaliações das disciplinas de seu curso.

Os enunciados desses itens, dois deles subdivididos em itens (um com duas questões, outro com cinco), regulam distintas respostas: onze delas informam quanto à frequência mediante a seleção de um ponto disposto em escala Likert, com cinco intervalos. Um dos demais itens, formulado sob a modalidade de múltipla escolha, estipula como resposta a seleção de apenas uma entre as quatro alternativas propostas. Os outros dois itens requerem a resposta afirmativa ou negativa, com a respectiva justificativa. As justificativas não foram analisadas neste trabalho. Por conseguinte, por participante foram previstas 14 respostas. O alfa de Cronbach obtido a partir das respostas dos participantes aos itens da escala apresentados neste trabalho foi de 0,74.

\section{Procedimento}

A aplicação do questionário foi coletiva em sala de aula, realizada em uma única sessão por série-curso, em 
horário normal de aula. Antes de iniciar a coleta, a pesquisadora explicou aos alunos presentes os objetivos e cuidados éticos relativos à confidencialidade dos dados, convidando-os a cooperarem voluntariamente. Todos que aceitaram assinaram o Termo de Consentimento Livre e Esclarecido antes de responderem ao questionário. Orientações gerais antecederam o preenchimento do questionário. O tempo médio gasto pelos participantes para responderem ao instrumento foi de 20 minutos.

\section{Resultados e Discussão}

A natureza exploratória, eminentemente descritiva, caracteriza o presente estudo que teve por objetivo verificar como alunos recém-ingressos e formandos de Biblioteconomia e Pedagogia percebem e leem os textos prescritos por seus professores. A análise desses dados teve por suporte a estatística descritiva.

A leitura é um processo multideterminado no qual concorrem os efeitos da história de cada um como leitor, do suporte e gênero do texto, da situação na qual e para a qual o texto se impõe ao sujeito como atividade e finalidade, bem como da valoração que ele atribui à leitura e a um texto particular, além da motivação para produzir essa atividade.

A apresentação dos resultados relativos ao conjunto das informações recolhidas segue esta ordem: experiência anterior em lerem textos como os prescritos no curso que realizam; principal fonte que move o interesse em lerem; uso posterior dos textos pelo professor; incentivo dos professores para que todos participem da discussão do texto em sala de aula; principal preocupação durante a leitura; adequação do modo de ler às formas de avaliação usadas por seus professores.

Os resultados relativos à experiência anterior em ler textos similares aos que são indicados nas disciplinas do curso demonstram que muitos participantes, Sempre ou Frequentemente, estudavam no Ensino Médio a partir de textos como os que atualmente lhes são indicados, conforme pode ser constatado na Tabela 1.
Nunca tiveram contato com esse tipo de texto no Ensino Médio. Ressalte-se, entretanto, que foram os participantes de GB os que mais informaram que estudavam, nesse nível de escolarização, Sempre/Frequentemente, a partir de textos similares aos prescritos nas atuais disciplinas do seu curso. Em contrapartida, os do GP, independente do ano em que se encontravam matriculados, foram os que assinalaram que tal experiência foi ocasional. Usando o mesmo instrumento utilizado neste estudo junto a alunos recém-ingressos e formandos dos cursos de licenciatura em Geografia, Letras Vernáculas e de Letras Estrangeiras da mesma IES onde este trabalho foi desenvolvido, Kito (2011) registrou que foram os formandos os que mais indicaram que Raramente ou Nunca liam esse tipo de texto no Ensino Médio. Possivelmente, essas diferenças entre recém-ingressos e formandos ocorram por ser mais frequente e recente a indicação dos professores do Ensino Médio para que seus alunos estudem a partir de textos similares aos indicados no Ensino Superior. Duas questões, entretanto, precisariam ser respondidas para explicar esses resultados quanto à similaridade percebida pelos participantes entre os textos indicados: ou no Ensino Médio passarem a ser recomendados para estudo textos acadêmicos, ou os textos recomendados não são desse gênero, isto é, textos acadêmicos. Para esta última questão, um dos indícios que sustentam sua formulação vem do estudo de Brito (2007), no qual a autora demonstrou que, nos cursos de licenciatura submetidos ao ENADE 2005 , dos 94.428 alunos que participaram, $67 \%$ informaram que a maioria dos seus professores usa apostilas, cópias de trechos ou resumos de livros como fontes para recomendarem a leitura em suas disciplinas.

A motivação em ler textos prescritos pode ser intrínseca ou extrínseca (Ryan \& Deci, 2000). A indicação do fator de interesse em realizar tais leituras pode ser interpretada como indício do tipo de motivação preponderante. Entre os participantes deste estudo, esse interesse depende: do professor que a indica (Frequentemente para 30\% do GB2; ocasionalmente para $36,4 \%$ do GP2); das condições que ele estipula quando prescreve textos (ocasionalmente para $31,4 \%$ do GB1, bem como para $50 \%$ do GP1 e do GP2); de como ele expõe o assunto tratado nos textos (Frequentemente para $50 \%$ do GB2 e $45,4 \%$ do GP2); do incentivo para a participação de todos na discussão do texto (Fre-

As informações da Tabela 1 permitem constatar que mais participantes do GB2 indicaram que Raramente ou

Tabela 1. Experiência de leitura no Ensino Médio de textos similares aos prescritos no curso de graduação (Valores em \%)

\begin{tabular}{cccccc}
\hline Grupos & Sempre & Frequentemente & $\begin{array}{c}\text { Algumas } \\
\text { vezes }\end{array}$ & Raramente & Nunca \\
\hline GB1 & 30,8 & 38.5 & 11,5 & 19,2 & - \\
GB2 & 31,8 & 13,6 & 13,6 & 36,4 & 4,5 \\
GP1 & 18,7 & 22 & 43,7 & 9,4 & 6,2 \\
GP2 & 20,8 & 12,5 & 45,8 & 16,7 & 4,2 \\
\hline
\end{tabular}


quentemente para $34,4 \%$ do GB1, $46,7 \%$ do GB2, $42,8 \%$ do GP1 e 45,4\% do GP2); da avaliação proposta pelo professor (Frequentemente para 37,5\% do GB1 e 45,4\% do GP2; ocasionalmente para $36,6 \%$ do GB2 e $39,3 \%$ do GP1). Destacadas as maiores frequências observadas, a leitura da Tabela 2 viabiliza constatar os índices sobre o reconhecimento dos participantes da força de cada um desses fatores para o seu interesse em realizar as leituras prescritas.

De modo geral, o interesse dos participantes em lerem os textos prescritos depende de fatores externos. Observe-se, na Tabela 2, que poucos foram os que indica- ram que esses fatores Raramente ou Nunca interferem. Em suma, pode-se dizer que os participantes parecem ser regulados por razões extrínsecas para produzirem as leituras que Ihes são recomendadas, comprometendo dessa forma a probabilidade de obterem melhores resultados em termos de aprendizagem e desempenho (Bzuneck, 2005).

Sendo essas as fontes que geram o interesse dos participantes em ler, analisemos agora a opinião deles acerca do uso desses textos em sala de aula.

Tabela 2. Razões aue movem os participantes a ler os textos prescritos por seus professores

\begin{tabular}{|c|c|c|c|c|c|c|c|c|c|c|c|c|c|c|c|c|c|c|c|c|}
\hline \multirow[t]{2}{*}{ Frequência } & \multicolumn{4}{|c|}{ do professor } & \multicolumn{4}{|c|}{$\begin{array}{l}\text { das condições que estipula } \\
\text { quando indica as leituras }\end{array}$} & \multicolumn{4}{|c|}{$\begin{array}{l}\text { de como o professor } \\
\text { expõe o assunto do texto }\end{array}$} & \multicolumn{4}{|c|}{$\begin{array}{l}\text { de como texto é discutido } \\
\text { em sala de aula }\end{array}$} & \multicolumn{4}{|c|}{$\begin{array}{c}\text { de como o professor } \\
\text { avalia }\end{array}$} \\
\hline & GB1 & GB2 & GP1 & GP2 & GB1 & GB2 & GP1 & GP2 & GB1 & GB2 & GP1 & GP2 & GB1 & GB2 & GP1 & GP2 & GB1 & GB2 & GP1 & GP2 \\
\hline Sempre & - & 3,3 & 7,1 & 9,1 & 6,2 & 3,3 & 3,6 & 9,1 & 12,5 & 6,7 & 14,4 & 13,6 & 13,3 & 13,3 & 17,8 & 22,7 & 15,6 & 9,4 & 17,8 & 18,1 \\
\hline Raramente & 34,4 & 26,7 & 21,4 & 22,7 & 28,1 & 13,3 & 17,9 & 4,5 & 21,9 & 3,3 & - & 9,1 & 6,7 & 6,6 & 10,7 & 4,5 & 15,6 & 23,3 & 10,7 & 13,6 \\
\hline Nunca & 25 & 13,3 & 28,6 & 4,5 & 3,8 & - & 3,6 & - & 3,1 & 3,3 & 10,7 & - & - & - & - & - & 6,2 & - & 3,6 & 4,5 \\
\hline
\end{tabular}

Tabela 3. Opinião dos participantes quanto ao uso posterior dos textos por parte dos professores (Valores em \%).

\begin{tabular}{c|c|c|c|c|c|c|c|c}
\hline \multirow{2}{*}{$\begin{array}{c}\text { Frequência } \\
\end{array}$} & \multicolumn{3}{|c|}{$\begin{array}{c}\text { Assuntos em pauta e trabalhados } \\
\text { anteriormente }\end{array}$} & \multicolumn{3}{c}{ Os conceitos propostos pelo autor } \\
\cline { 2 - 9 } & GB1 & GB2 & GP1 & GP2 & GB1 & GB2 & GP1 & GP2 \\
\hline Sempre & 21,9 & 13,3 & 33,3 & 9,1 & 28,1 & 16,7 & 22,2 & 4,5 \\
Frequentemente & 59,4 & 43,3 & 59,2 & 40,9 & 53,1 & 26,7 & 55,5 & 36,4 \\
Às vezes & 18,7 & 36,7 & 7,4 & 45,4 & 15,6 & 46,7 & 22,2 & 50 \\
Raramente & - & 6,7 & - & 4,5 & 3,1 & 10 & - & 9,1 \\
\hline
\end{tabular}

Um dos indícios de como os professores trabalham os assuntos em sala de aula é o da frequência com que ele estabelece vínculos com os textos que prescreve para estudo. Na opinião de mais da metade dos participantes dos dois cursos, ou seja, para $51,6 \%$ do GB e 51\% do GP, seus professores costumam estabelecer essas relações.

A Tabela 3 sumariza os resultados das respostas dos participantes quanto a esse aspecto, por curso e ano. Como nela expresso, de modo geral, os participantes percebem que seus professores relacionam as informações dos textos a assuntos trabalhados anteriormente, explorando os conceitos propostos pelos autores dos textos indicados. Merece destaque o fato de que são os participantes do primeiro ano, de ambos os cursos, os que mais informaram que os professores Frequentemente/Sempre se preocupam em relacionar os textos com os assuntos trabalhados em sala de aula. Os participantes matriculados no último ano percebem que essas ações do professor acontecem Às vezes, (36,7\% do GB2; $45,4 \%$ do GP2; $46,7 \%$ do GB2; $50 \%$ do GP2).

$\mathrm{O}$ incentivo dos alunos para produzirem a leitura dos textos prescritos em parte pode estar relacionado a outros modos de trabalho em sala de aula, tendo-os como referência. Por exemplo, às discussões propostas e instigadas pelo professor. Somente um aluno do GB1 não respondeu a essa questão. Portanto, o total de respostas usado para a análise dos resultados foi 61 nesse subgrupo. Conforme pode ser 


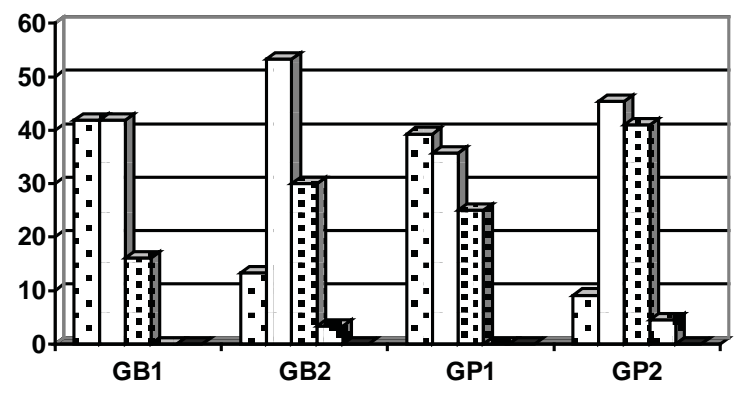

\begin{tabular}{|l|}
\hline$\square$ Sempre \\
$\square$ Frequentemente \\
$\square$ Algumas vezes \\
$\square$ Raramente \\
$\square$ Nunca \\
\hline
\end{tabular}

Figura1. Opinião dos participantes quanto ao esforço dos professores para que a maioria dos alunos participe na discussão dos textos.

constatado na Figura 1, mais participantes veteranos do que recém-ingressos informaram que Frequentemente seus professores demonstram se preocupar com que a maioria dos alunos participe da discussão dos textos em sala de aula. Merece destaque que, para $41 \%$ dos participantes de GP2, esse esforço por parte do professor ocorre ocasionalmente.

A efetiva participação dos alunos nas discussões propostas por seus professores em torno do texto depende ou deveria depender da leitura prévia dos alunos. A produção ou não dessas leituras pode ser examinada pela preocupação que os regula quando leem e pela relação entre essa realização com as formas de avaliação a que serão submetidos.

Solicitados a identificar a principal preocupação que tinham ao ler textos de estudo, identificando a alternativa que melhor a expressasse, os participantes deveriam optar apenas por uma. Não obstante, seis participantes assina- laram mais de uma e um não respondeu. Os resultados apresentados referem-se aos que atenderam ao solicitado.

A principal preocupação dos participantes do GB e do GP (105 respondentes), ao lerem um texto indicado por professores, é a de compreendê-lo, relacionando-o a conhecimentos anteriores (40,9\%). Apenas um participante do GP2 utilizou a opção de usar as próprias palavras para informar sua principal preocupação ao ler textos de estudo, a qual transcrevemos: Auxiliar minha compreensão nas aulas e nas avaliações.

Para $62,5 \%$ do GB2 e $36,4 \%$ do GP2, compreender o texto relacionando-o a conhecimentos prévios é a razão que Frequentemente inquieta-os ao ler. Poucos, com exceção de $46,9 \%$ do GB1, se preocupam em ler para reproduzirem posteriormente as informações do texto. A Tabela 4 informa a distribuição das respostas por tipo de preocupação que regula a leitura desses textos.

Tabela 4. Principal preocupação na leitura de textos de estudo.

\begin{tabular}{|c|c|c|c|}
\hline Grupos & $\begin{array}{c}\text { Interpretar o que o } \\
\text { autor escreveu para } \\
\text { poder reproduzir essas } \\
\text { informações. }\end{array}$ & $\begin{array}{c}\text { Compreender o texto, } \\
\text { relacionando-o a } \\
\text { conhecimentos prévios. }\end{array}$ & $\begin{array}{c}\text { Compreender o texto, buscando identificar } \\
\text { as estratégias e ou argumentos usados } \\
\text { pelo autor para conduzir à conclusão que } \\
\text { propõe. }\end{array}$ \\
\hline GB1 $(n=32)$ & $46,9 \%$ & $21,9 \%$ & $31,2 \%$ \\
\hline GB2 $(n=24)$ & $12,5 \%$ & $62,5 \%$ & $25 \%$ \\
\hline GP1 $(n=27)$ & $25,9 \%$ & $29,6 \%$ & $44,4 \%$ \\
\hline GP2(n=22) & - & $59,1 \%$ & $36,4 \%$ \\
\hline
\end{tabular}

Tabela 5. Adequação dos modos de ler às formas de avaliar adotadas pelo professores (Valores em \%).

\begin{tabular}{|c|cccccc|}
\hline Grupos & Sempre & Frequentemente & $\begin{array}{c}\text { Algumas } \\
\text { vezes }\end{array}$ & Raramente & Nunca \\
\hline GB1 $(n=30)$ & 10 & 30 & 53,3 & 3,3 & 3,3 \\
\hline GB2 $(n=23)$ & 4,3 & 17,4 & 52,2 & 26,1 & - \\
\hline GP1 $(n=27)$ & 14,8 & 41 & 33,3 & 7,4 & 3,7 \\
\hline GP2 $(n=22)$ & 18,2 & 27,3 & 45,4 & 9,1 & - \\
\hline
\end{tabular}


As respostas ao item no qual deveriam informar a frequência com que ajustavam seus modos de ler ao tipo de avaliação adotada pelo professor não foram informadas por $11,7 \%$ dos participantes do GB e por $2 \%$ do GP. Dentre os que responderam, $52,8 \%$ do GB e $38,8 \%$ do GP indicaram que ocasionalmente costumam adequar a leitura dos textos indicados às formas que os professores adotam para avaliar.

Pode-se constatar, na Tabela 5, que, independentemente do curso e ano em que os participantes se encontravam matriculados, poucos foram os que admitiram que Nunca/ Raramente ajustam seus modos de ler os textos prescritos ao tipo de avaliação adotado por seus professores. Em ambos os cursos, apenas alguns dos participantes do último ano selecionaram a opção Nunca.

Como se sabe, as experiências vivenciadas nas avaliações são fontes geradoras de ansiedade que afetam negativamente tanto o desempenho acadêmico como a autoestima dos estudantes (Cunha \& Carrilho, 2005). Em assim sendo, os modos como leem (Tabela 4) pode ser um indício da percepção que os participantes têm acerca do que seja importante para um bom desempenho acadêmico, bem como do tipo de avaliação a que são submetidos. Os resultados obtidos parecem sustentar a hipótese da dependência da realização da leitura com as formas adotadas pelos professores para avaliar. Isso porque, para mais de $50 \%$ dos participantes de GP1, Sempre ou Frequentemente as formas de avaliação adotadas pelos professores interferem nos modos de ler. Essa relação é reconhecida como ocasional com o maior índice entre os participantes de GB (53,3\% do GB1; $52,2 \%$ do GB2) e por $45,4 \%$ do GP2.

Como relatado, a preocupação quanto a serem capazes de reproduzir as informações do texto de estudo é maior entre os recém-ingressos (46,9\% do GB1; $25,9 \%$ do GP1), ainda que presente para $25,9 \%$ dos formandos em Pedagogia. Essa leitura é, ainda, regulada Sempre, Frequentemente ou Às vezes pelas formas de avaliação adotadas (vide Tabela 5). Uma explicação possível para esse conjunto de resultados faculta que proponhamos a hipótese de que o modo de enfrentamento para as dificuldades que encontram no Ensino Superior, especialmente dos recém-ingressos, seja a de memorizarem as informações dos textos prescritos para estudo.

Contudo, esses modos de ler não favorecem a oportunidade dos alunos realizarem a leitura como uma "estratégia metodológica” (Colom-Cañellas \& Touriñán-López, 2009, p. 455) que mobilize a aprendizagem. Neste estudo, o modo e as razões informadas pelos participantes para realizarem as leituras prescritas (Tabelas 4 e 2) podem comprometer as condições de organização e fortalecimento das suas capacidades cognitivas, evidenciando a possível ausência de uso da leitura como estratégia metodológica para aprenderem autonomamente, visto que são preponderantemente motivados extrinsecamente para realizá-la. Por sua vez, tais comportamentos comprometem o desenvolvimento de repertórios importantes, que interferem no seu desempenho acadêmico e autoestima.

Roger Chartier explica que a leitura não ocorre separada da materialidade que se estabelece entre o "mundo do texto" e o "mundo do leitor" (1991, p. 178), uma vez que nem o texto nem os modos de ler são entidades abstratas e universais. A organização do objeto que contém o texto dirige o leitor em sua leitura, bem como em sua "apreensão e compreensão" (Chartier, 1991, p. 178). Essas atividades, isto é, as de tomar para si e compreender, sempre ocorrem em um jogo inscrito num espaço situado, que dirige o leitor na "relação consigo ou com o outro" (Chartier 1991, p.181).

Se a organização do texto dirige em parte as ações do leitor, não menos importantes são as condições que o professor estipula quando indica um texto de estudo. Essas foram reconhecidas mais pelos alunos formandos do que pelos recém-ingressos como razões que os influenciam Frequentemente/Sempre a ler (Tabela 2).

Os resultados deste estudo sugerem que a maioria dos participantes veio a ter mais contato com textos acadêmicos somente no Ensino Superior. Esses resultados, apesar de previstos na literatura pertinente (Carlino, 2003), indiretamente permitem supor a ausência de textos dessa natureza na escolarização anterior.

Como ensina Witter (1992), a produção de textos acadêmicos implica no atendimento a exigências diversas, algumas reguladas por campo disciplinar (Carlino, 2003; Mustafa, 2004). Essas produções exigem modos de ler que nem sempre são ensinados, inclusive em cursos superiores.

A leitura não é movida apenas por aspectos cognitivos. Como as demais atividades, a leitura ocorre pelos efeitos do conjunto das dimensões afetivas que integram a motivação para realizá-la, entre estas as do valor a ela atribuída (Brophy, 1999; Linnenbrink \& Pintrich, 2004).

Segundo Brophy (1999), o conhecimento derivado de diversas teorias motivacionais contemporâneas permite afirmar que uma determinada atividade ou conhecimento terá o potencial de motivar os alunos, na medida em que seja percebida como algo de grande valor e se constitua, para quem a realize, em uma tarefa autêntica. No caso deste estudo, os estudantes devem valorizar as atividades que precisam realizar. Quando eles apreciam a atividade que deve ser cumprida, isto é, quando a valorizam, esse sentimento é uma ótima razão para que se envolvam na sua realização.

Nesta investigação, verificamos, ainda, que os participantes, desde que ingressaram no curso no qual estavam matriculados, aumentaram o gosto pela leitura de textos como os que lhes são prescritos no curso que realizam. O item pertinente do questionário proporcionava duas opções de resposta (Sim; Não). Não responderam a esse item 10 participantes. A maioria dos respondentes informou que o gosto por ler esses textos tinha aumentado desde o ingresso no curso (78,1\% do GB1; $63,3 \%$ do GB2; $60,7 \%$ do GP1; $63,6 \%$ do GP2). Contudo, para alguns (12,5\% do GB1; $20 \%$ do GB2; $28,6 \%$ do GP1; $31,8 \%$ do GP2), o ingresso no curso não modificou o gosto por esse tipo de leitura. Apesar das possíveis dificuldades que os participantes possam ter vivenciado ao lerem esses textos, o fato de a terem que realizar parece ter interferido positivamente no gosto em lerem os textos que lhes são prescritos. 


\section{Considerações Finais}

Como demonstrado neste trabalho, os modos como os professores prescrevem a leitura dos textos para estudo e os trabalham posteriormente parecem interferir no modo, interesse e na preocupação dos alunos quando os leem. Esses resultados convergem, por exemplo, com os observados por Bartalo (1997).

Tem sido comum a queixa de alunos de cursos de graduação quanto às dificuldades que enfrentam para cumprir as exigências de leitura dos textos que lhes são prescritos pelos seus professores. Alguns apontam a falta de tempo para realizá-las, outros porque não compreendem as informações dos textos e a importância das mesmas para a sua formação e atividades profissionais futuras. Como apresentado na revisão da literatura pertinente (Barzotto, 2005; Carlino, 2003; Santos \& Oliveira, 2004; Vicentelli, 1999) e confirmado pelos resultados expressos nas Tabelas 2 a 5, faz-se urgente e necessária a reflexão dos professores sobre os modos como prescrevem e utilizam os textos que indicam a seus alunos para estudo.

Paulo Freire (1982) sugere que quem estuda deve se sentir desafiado pelo texto em sua totalidade e se apropriar de sua significação. Como demonstrado neste trabalho, a principal preocupação e o interesse em ler os textos prescritos pelos professores parecem estar relacionados aos modos como os professores prescrevem e trabalham em sala de aula os textos que recomendam para estudo. Em assim sendo, esses profissionais precisam estar atentos a como prescrevem e trabalham os textos que indicam.

Para Charlot (2003), o valor e o sentido do saber originam-se das relações que ele implica. Nessa perspectiva, ao lerem, os estudantes deveriam estabelecer relações teóricas e práticas com o saber, as quais poderiam surgir das relações que estabeleçam com o texto, evidenciando a sua mobilização como leitor. Entretanto, essa mobilização se dá em função, também, da atividade e da situação na qual a leitura foi proposta. Daí a importância do cuidado que os professores devem tomar ao prescrever leituras.

Não se pode ignorar que as circunstâncias nas quais são produzidas as leituras de estudo são contingenciadas, também, pelos hábitos, estilos, atitudes e pelo tipo de motivação dos alunos para estudar, os quais desempenham um papel crítico e central no desempenho acadêmico dos estudantes (vide revisão da literatura de Credé \& Kuncel, 2008, por exemplo).

Deve ser lembrado, ainda, que as experiências vivenciadas por alunos, desde o ingresso em cursos de Ensino Superior, nem sempre condizem com as suas expectativas.

A maioria dos estudantes que ingressam no ensino superior traz consigo uma expectativa positiva em relação a sua futura experiência acadêmica. $E$ a discordância entre estes sentimentos e pensamentos e o que a universidade efetivamente pode oferecer gera uma fonte de dificuldades refletida na adaptação, na satisfação e no sucesso acadêmico. (Cunha \& Carrilho, 2005, p. 216).
Talvez esse descompasso entre o que de fato é oportunizado em cursos de graduação e as expectativas dos que neles conseguem ingressar explique, pelo menos em parte, as relações descritas entre os modos de ler e a principal preocupação que os participantes deste estudo informaram. Entre os fatores analisados, merece destaque o trabalho do professor em sala de aula relativo às leituras que indica: como relaciona os assuntos aos textos que prescreve, como os discute, quais formas utiliza para avaliar o desempenho dos alunos. Ademais, os resultados da Tabela 2 justificam a relevância dos cuidados que esse profissional deve ter quando prescreve leituras para seus alunos.

Neste estudo, apresentamos de que modo alunos de dois cursos de graduação, Biblioteconomia e Pedagogia, percebem como os professores trabalham os textos que recomendam, o que os move a ler textos de estudo, suas preocupações e razões. De modo geral, os resultados convergem com estudos anteriores que usaram o mesmo instrumento de coleta e realizados junto a licenciaturas.

O conjunto de dados e a literatura pertinente permitem a defesa da proposição de uma pedagogia da leitura no desenvolvimento dos currículos ofertados em cursos de graduação, resumida por Carvalho (2002) nestas palavras: "uma preparação teórico-prática em matéria de leitura, [a qual] não seria proporcionada por uma disciplina específica, mas por experiências de aprendizagem vivenciadas ao longo dos cursos" (Carvalho, 2002, p. 2, grifos nossos).

Como argumentado, a leitura é uma atividade que subsidia a formação pessoal e profissional. Para que ela ocorra, o leitor precisa ser mobilizado tanto pelo assunto do texto quanto pela situação na qual ele é desafiado a realizá-la. A produção da leitura precisa, além de ser motivada, ser ensinada e valorizada.

Apesar das limitações deste trabalho, algumas delas decorrentes do instrumento utilizado, outras das análises realizadas, exclusivamente descritivas, a importância de investigações que tenham por foco as práticas e os modos de ler de estudantes universitários é fundamental para a proposição de ações preventivas e remediativas de leitura, especialmente das relacionadas a textos acadêmicos como os que devem ser usados em cursos de Ensino Superior.

\section{Referências}

Amorim, G. (Org.). (2008). Retratos da leitura no Brasil. São Paulo: Imprensa Oficial: Instituto Pró-Livro.

Bartalo, L. (1997). Comportamento de leitura de estudantes de Biblioteconomia. Dissertação de Mestrado, Universidade Estadual de Londrina, Londrina, Paraná.

Barzotto, V. H. (2005). Leitura e interpretação de textos para alunos ingressantes no terceiro grau. Em R. C. de C. P. Lima (Org.), Leitura: Múltiplos olhares (pp. 97-101). Campinas, SP: Mercado de Letras. 
Brito, M. R. de. (2007). ENADE 2005: Perfil, desempenho e razão da opção dos estudantes pelas licenciaturas. Avaliação, 12(3), 401443.

Brophy, J. (1999). Toward a model of the value aspects of motivation in education: developing appreciation for particular learning domains and actives. Educational Psychologist, 39(2), 75-85.

Bzuneck, J. A. (2005). A motivação dos alunos em cursos superiores. Em M. C. E. A. Joly, A. A. A. dos Santos \& F. F. Sisto (Orgs.), Questões do cotidiano escolar (pp. 217-237). São Paulo: Casa do Psicólogo.

Carlino, P. (2003). Alfabetización acadêmica: um cambio necesario, algunas alternativas posibles. Educere, 6(20), 409-420.

Carvalho, M. (2002). A leitura dos futuros professores: por uma pedagogia da leitura no ensino superior. Teias, 3(5), 1-19.

Charlot, B. (2003). O sujeito e a relação com o saber. Em R. L. Barbosa (Org.), Formação de educadores: Desafios e perspectivas (pp. 2333). São Paulo: Edunesp.

Chartier, R. (1991). O mundo das representações. Estudos Avançados, 11(5), 173-191.

Chartier, A-M, Debayle, J., \& Jachimowicz, M-P. (1993). Lectures pratiquées et lectures déclarées: reflexions autour d'une enquête sur les étudiants en IUFM. Em E. Fraisse (Org.), Les étudiantes et la lecture (pp. 73-98). Paris: Presses Universitaires de France.

Colom-Cañellas, A., \& Touriñán-López, J. M. (2009). La lectura en el siglo XXI. Recuperado: 15 de mar. 2009. Disponível: http://www. ucm.es/info/site/docu/26site/actas26site.pdf.

Credé, M., \& Kuncel, N. R. (2008). Study habits, skills, and attitudes: the third pillar supporting collegiate academic performance. Perspectives on Psychological Science, 3(6), 425-453.

Cunha, S. M., \& Carrilho, D. M. (2005). O processo de adaptação ao ensino superior e o rendimento acadêmico: adaptação e rendimento acadêmico. Psicologia Escolar e Educacional, 9( 2),215-224.

Cunha, N. B., \& Santos, A. A. A. (2006). Relação entre a compreensão da leitura e a produção escrita em universitários. Psicologia: Reflexão e Crítica, 19(2), 237-245.

Dauster, T. (2003). A invenção do leitor acadêmico: quando a leitura é estudo. Leitura: teoria e prática, 41,73-83.

Fraisse, E. (1993). Les chemins de la lecture à l'université. Em E. Fraisse (Org.), Les étudiantes et la lecture (pp. 241-252). Paris: Presses Universitaires de France.

Freire, P. (1982). Considerações em torno do ato de estudar. Em P. Freire, Ação cultural para a liberdade e outros escritos (6a ed., pp.
9-12). Rio de Janeiro: Paz e Terra.

Gomes, M. A. M. dos, \& Boruchovitch, E. (2009). Proficiência em leitura: um panorama da situação. Em A. A. A. dos Santos, E. Boruchovitch \& K. L. de Oliveira Cloze: um instrumento de diagnóstico e intervenção (pp. 23-46). São Paulo: Casa do Psicólogo.

Joly, M. C. R. A., \& Paula, L. M. de. (2005). Avaliação do uso de estratégias de aprendizagem e a compreensão da leitura em universitários. Em M. C. R. A. Joly, A. A. A. dos Santos \& F. F. Sisto (Orgs.), Questões do cotidiano universitário (pp. 33-57). São Paulo: Casa do Psicólogo.

Kito, T. (2011). Práticas de leitura de futuros professores (Relatório Final PIBIC/UEL). Londrina, Universidade Estadual de Londrina, Paraná.

Kons, M. L. (2005). Vestígios de poder em práticas de leitura. Revista da UFG, 7(2), 1-10

Linnenbrink, E. A., \& Pintrich, P. R. (2004). Role of affect in cognitive processing in academic contexts. Em D. Y. Dai \& R. J. Sternberg (Orgs.), Motivation, emotion and cognition (pp. 57-87). New Jersey: Lawrence Erbaum Associates.

Mostafa, S. P. (2004). O artigo de ciência como fato e artefato cultural. Educação Temática Digital, 6(1), 68-80.

Oliveira, M. H. M. (1999). Comportamento de leitura do estudante universitário. Em G. P. Witter (Org.), Leitura: textos e pesquisas (pp. 125-139). Campinas, SP: Alínea.

Oliveira, K. L. de, Santos A. A. A. dos, \& Primi, R. (2003). Estudo das relações entre compreensão em leitura e desempenho acadêmico na universidade. Interação em Psicologia, 7(1), pp. 19-25.

Oliveira, K. L. de, \& Santos, A. A. A. dos. (2005). Compreensão em leitura e avaliação da aprendizagem em universitários. Psicologia: Reflexão e Crítica, 18(1), 118-124.

Pullin, E. M. M. P. (2006). Questionário: Prescrições, controles e práticas de leitura de estudo. Relatório técnico do Projeto de pesquisa - Metacognição, práticas de leitura e estratégias de estudo em estudantes de um curso de formação de professores - possíveis efeitos de um programa de intervenção. Universidade Estadual de Londrina, Londrina, Paraná.

Pullin, E. M. M. P. (2007). Leitura de estudo: estratégias reconhecidas como utilizadas por alunos universitários. Ciências \& Cognição 4 , 51-61.

Pullin, E. M. M. P., \& Tanzawa, E. C. L. (2009). Como alunos de graduação avaliam os textos prescritos por seus professores: um estudo junto a dois cursos de graduação. Anais do $17^{\circ} \mathrm{COLE}$ Congresso de Leitura do Brasil (pp. 1-11). Campinas, SP: ALB. 
Ryan, R. M., \& Deci, E. L. (2000). Intriinsic and extrinsic motivations: Classics definions and new directions. Contemporany Educational Psychology, 25, 54-67.

Santos, A. A. A. dos, \& Oliveira, K. L. de. (2004). A importância da compreensão em leitura para a aprendizagem de universitários. Em E. Boruchovitch \& J. A. Bzuneck (Orgs.), Aprendizagem: processos psicológicos e o contexto social na escola (pp. 119149). Petrópolis, RJ: Vozes.

Silva, E. M. T., \& Witter, G. P. (2008). Compreensão de texto e desempenho acadêmico em estudantes de psicologia. Estudos de Psicologia, 25(3), 395-403.

Silva, E. T da. (1996). O ato de ler (7a ed.). São Paulo: Cortez.

Tanzawa, E. C. L. (2009). Leitura e compreensão de textos acadêmicos: um estudo junto a alunos de dois cursos de graduação. Dissertação de Mestrado, Universidade Estadual de Londrina, Londrina, Paraná.

Vicentelli, H. (1999). Problemática de la lectura en estudiantes universitarios. Psicologia Escolar e Educacional, 3, 195-202.

Witter, G. P. (1992). Produção e leitura do texto científico. Estudos de Psicologia, 9(1), 19-26.

Witter, G. P. (1996). Avaliação da produção sobre leitura na universidade (1989/1994). Psicologia Escolar e Educacional, 1(1), 31-38.

Elaine Cristina Liviero Tanzawa (tanzawa@hotmail.com)

Bibliotecária do Instituto Cultural Brasil Estados Unidos - Londrina, Mestre em Educação (UEL)

Elsa Maria Mendes Pessoa Pullin (pullin@uel.br)

Universidade Estadual de Londrina, Doutora em Psicologia Escolar e do Desenvolvimento Humano (IPUSP) 